\title{
Studying the impact of alkaline sulfide leaching parameters upon the efficiency of arsenic recovery from copper skimmings of lead production
}

\author{
A. A. Tymbayeva, PhD Student ${ }^{1}$, Chief Specialist at the Research Center of Ust-Kamenogorsk Metallurgical Complex ${ }^{3}$ \\ e-mail: aigerimnabiyeva92@gmail.com \\ S. V. Mamyachenkov, Professor, Head of the Department of Non-Ferrous Metals Metallurgy², \\ e-mail: svmamyachenkov@yandex.ru \\ S. A. Bannikova, Head of the Research Center of Ust-Kamenogorsk Metallurgical Complex ${ }^{3}$, \\ e-mail: sbannikova@kazzinc.com \\ O. S. Anisimova, Associate Professor at the Department of Non-Ferrous Metals Metallurgy ${ }^{2}$ \\ ${ }^{1}$ D. Serikbayev East Kazakhstan State Technical University, Ust-Kamenogorsk, Republic of Kazakhstan. \\ ${ }^{2}$ Ural Federal University named after the First President of Russia B. N. Yeltsin, Yekaterinburg, Russian Federation. \\ ${ }^{3}$ Kazzinc Ltd., Ust-Kamenogorsk, Republic of Kazakhstan.
}

\begin{abstract}
The article is concerned with the problem of arsenic circulation as copper skimmings of lead production - the product of the lead bullion decopperization process at a metallurgical complex, uniting copper and lead plants. A brief overview of the methods of processing arsenic-containing middling products for the purpose of arsenic removal is given; the main advantages and disadvantages are indicated.

The possibility of processing copper skimmings by the method of alkaline sulfide leaching with separation into arseniccontaining solution and lead-copper precipitate is studied. The results of the researches into the influence of temperature, process duration, solids content in the pulp, particle size, and the ratio of sodium hydroxide to elemental sulfur in the alkaline sulfide reagent on the process of alkaline sulfide leaching of copper skimmings af lead production are provided. Within the studied range of varied factors, the highest indexes of arsenic extraction into solution (85.04\%) were achieved under the following conditions: temperature $-85^{\circ} \mathrm{C}$, duration -4 hours, solids content in the pulp $-350 \mathrm{~g} / \mathrm{dm}^{3}$, fraction $(-0.08 \mathrm{~mm}), \mathrm{NaOH} / \mathrm{S}$ ratio $=100 \mathrm{~g} / 100 \mathrm{~g}$ in $1 \mathrm{dm}^{3}$ of the solution.

The proposed method for processing copper skimmings will allow one to selectively isolate arsenic into the dump waste product during subsequent precipitation and separate contaminant from lead-copper cake, into which precious metals also pass. Such an approach provides the reduction of arsenic circulation between the lead and copper manufacturing facilities.

Key words: arsenic, alkaline sulfide leaching, copper skimmings of lead production, hydrometallurgical processing, sodium polysulphides, arsenic-containing middling products, sodium hydroxide, copper-lead cake.

DOI: $10.17580 / \mathrm{nfm} .2020 .02 .03$
\end{abstract}

\section{Introduction}

$\mathrm{T}$ The issue of processing integrated polymetallic raw materials with a high content of impurities, in particular arsenic, is to date one of the currently central fields in metallurgy of non-ferrous metals. The development of technologies aimed at reducing the circulation of arsenic between the manufacturing divisions of non-ferrous metal industry is one of the main tasks for researchers working in this area.

Analysis of the state of technologies for processing polymetallic raw materials by the example of a metallurgical complex uniting copper and lead plants [1] has revealed the problem of arsenic circulation between two plants in the form of copper skimmings of lead production.

Despite the existence of a significant base of developments devoted to the study of the problem of processing arsenic-containing materials, the issue of removing arsenic from copper skimmings of lead production to the dump waste product has not been considered because of the low (in the past) arsenic content in them [1].
When sintering machine as the primary smelting unit at lead production is substituted for the furnace with top submerged lance Isasmelt, which allows to achieve a high degree of desulphurisation of the material and to increase the copper content in the charge in connection with the deterioration in the quality of supplied raw materials, resulting production slag from the furnace with top submerged lance contains more copper and only negligible amounts of sulfur. Lead bullion obtained by melting of this slag in a shaft furnace is characterized by the same chemical properties. In the process of decopperization of this lead bullion, copper reacts mainly with arsenic due to a lack of sulfur, and in the form of intermetallides and metallic copper passes into copper skimmings (dross), thereby leading to a change in the distribution of arsenic at this processing stage.

If earlier the process flowsheet has assumed the arsenic distribution into lead bullion at the stage of rough decopperization with manufacturing arsenic waste and its further burial, then the scheme has been changed because of high content of copper and almost complete absence of sulfur 
in lead bullion. According to it, about $\sim 83 \%$ of arsenic from loading to the lead plant goes to copper skimmings of lead production during its rough decopperization. Copper skimmings are then subjected to electrosmelting to obtain a matte-speiss mixture, into which about $55 \%$ of arsenic (from the load to the lead plant) passes with raw materials. At that, the arsenic supplied to the copper plant with raw materials is almost completely distributed into powdergas mixture of the primary melting unit, which is further processed with the production of a dump waste containing arsenic and iron (Fig. 1).

According to the literature sources, there are no methods for processing dry copper slurry to remove arsenic. Despite a number of advantages, pyrometallurgical methods for treating arsenic-containing materials are generally characterized by high dust entrainment, which is negatively affecting the ecology of the region and demanding the installation of expensive dust catching equipment, as well as high spending caused by working at high temperatures.

In this case, hydrometallurgical processing is a relatively inexpensive and more environmentally friendly method. Leaching in water, sulfuric acid [3-6, 11], an alkaline sulfide reagent $[7-9,11]$, a solution of sodium hydroxide[10], hydrochloric acid [5], and nitric acid [5, 11] are the most widely used methods of hydrometallurgical processing of arsenic-bearing middling products.

Depending on the purpose of leaching, each hydro- metallurgical method for processing arsenic-bearing materials has its own advantages and disadvantages. For example, sulfuric acid is the most common and inexpensive reagent used for leaching arsenic-bearing materials, but it does not provide selectivity of converting arsenic into solution [13]. Not only arsenic, but copper, zinc and other non-ferrous metals also pass into the solution, and their further precipitation from it leads to the inclusion of additional stages into the process.

In comparison with sulfuric acid, an alkaline sulfide solution implies higher expenses. At the same time, alkaline sulfide leaching ensures selectivity of arsenic conversion into solution, and also reduces the process time [3].

In this paper, a hydrometallurgical method for selective arsenic removal from copper skimmings of lead production, which will reduce arsenic circulation between lead and copper production facilities, is investigated.

The aim of this paper is to determine optimal parameters of alkaline sulfide leaching of copper skimmings of lead production that ensure the most complete arsenic extraction into solution.

\section{Object and method of research}

Copper skimmings of lead production have been selected as an object of our study; their composition is as follows, \%: $3.88 \mathrm{As} ; 1.73 \mathrm{Sb}$; $18.95 \mathrm{Cu}$; $63.70 \mathrm{~Pb}$; $2.83 \mathrm{~S}$; $1.45 \mathrm{Zn} ; 1.12 \mathrm{Fe} ; 22.90 \mathrm{~g} / \mathrm{t} \mathrm{Au} ; 2912.06 \mathrm{~g} / \mathrm{t} \mathrm{Ag}$.

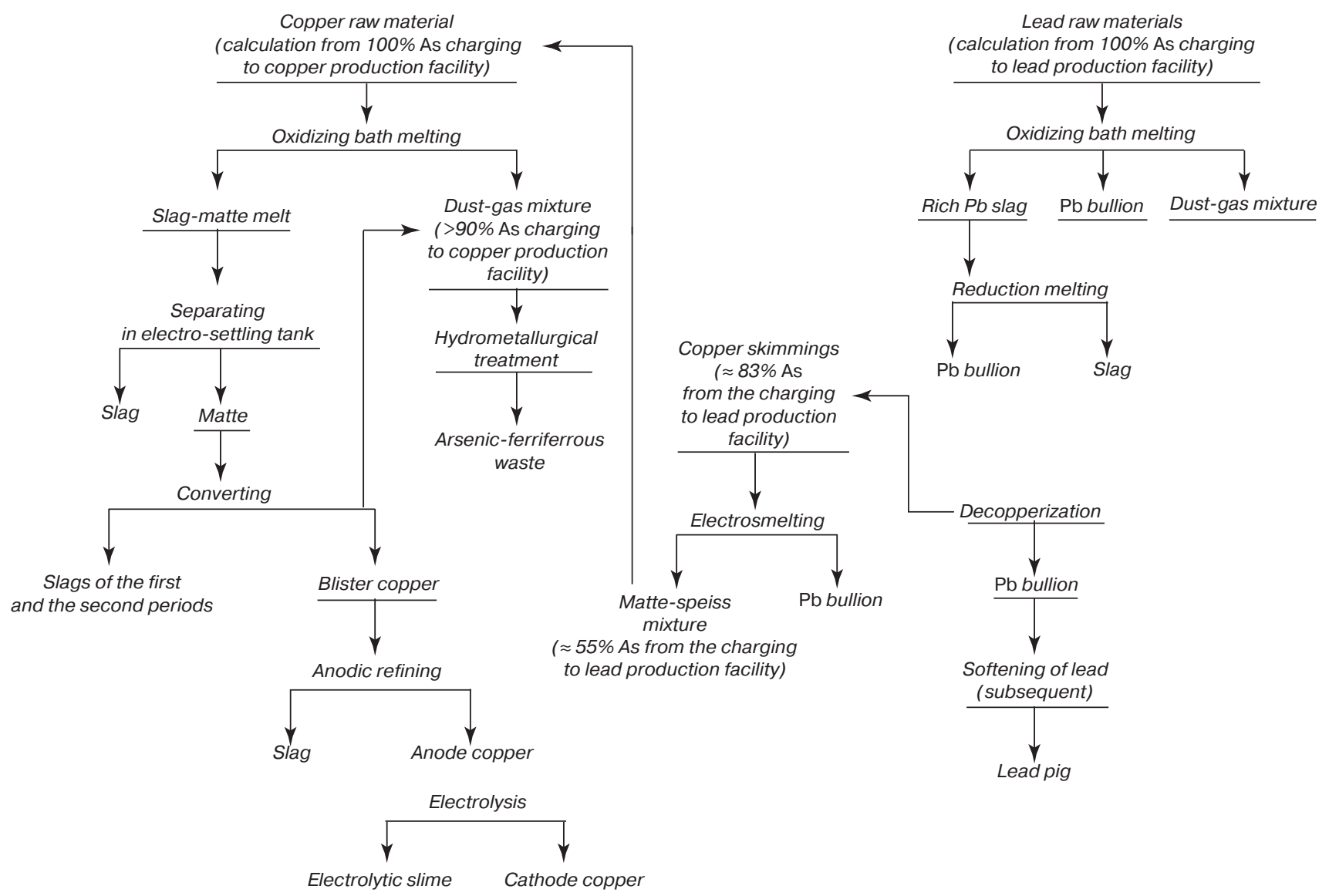

Fig. 1. The basic process flowsheet of copper and lead production indicating the main flows of arsenic circulation 
The phase composition of copper skimmings of lead production was studied using an OLYMPUS BX51 microscope. The results of chemical phase analysis have showed that arsenic is presented in elemental state and in the form of intermetallic compounds (78.89 mass \%) and as sulfides and sulfosalts (21.11 mass \%); antimony is presented as sulfides and sulfosalts (62.11 mass\%), and in the elemental condition (37.89 mass \%); content of copper is 21.41 mass $\%$ in the form of sulfides and sulfosalts, 52.45 mass $\%$ in the form of intermetallic compounds, and 25.51 mass $\%$ in the metallic state; lead presence in the metallic state amounts to 80.77 wt. $\%$, in the form of oxides and silicates is $9.64 \mathrm{wt} . \%$, and $9.59 \mathrm{wt} . \%$ gives the form of sulfides and sulfosalts.

A sample of copper skimmings of lead production was crushed in a laboratory jaw crusher, fine crushed in a ball mill, and bolted dry on a sieve with the meshes of $0.08-0.315 \mathrm{~mm}$.

The alkaline sulfide reagent solution was prepared by dissolving sodium hydroxide of a p.a. qualification in water at room temperature, followed by an increase the temperature above $90{ }^{\circ} \mathrm{C}$ and batch charging of elemental sulfur on being continuously stirred. The process of preparing an alkaline sulfide reagent proceeds according to the following reaction equations:

$$
\begin{aligned}
& 4 \mathrm{~S}^{0}+6 \mathrm{NaOH} \rightarrow 2 \mathrm{Na}_{2} \mathrm{~S}+\mathrm{Na}_{2} \mathrm{~S}_{2} \mathrm{O}_{3}+3 \mathrm{H}_{2} \mathrm{O}, \\
& (x-1) \mathrm{S}^{0}+\mathrm{Na}_{2} \mathrm{~S} \rightarrow \mathrm{Na}_{2} \mathrm{~S}_{x}(\text { where } x=2 \text { to } 5) .
\end{aligned}
$$

During the subsequent alkaline sulfide leaching of dry copper dross, the conversions may occur as follows:

$$
\begin{aligned}
& 2 \mathrm{Cu}_{3} \mathrm{As}+\mathrm{Na}_{2} \mathrm{~S}_{x}+(x+3) \mathrm{S}^{0} \rightarrow \\
& \left.\rightarrow 2 \mathrm{NaAsS}_{x}+3 \mathrm{Cu}_{2} \mathrm{~S} \text { (where } x=2 \text { to } 5\right), \\
& 2 \mathrm{Fe}_{2} \mathrm{As}+\mathrm{Na}_{2} \mathrm{~S}_{x}+(x+4) \mathrm{S}^{0} \rightarrow \\
& \left.\rightarrow \mathrm{NaAsS}_{x}+4 \mathrm{FeS} \text { (where } x=2 \text { to } 5\right), \\
& 2 \mathrm{CuPbAsS}_{3}+\mathrm{Na}_{2} \mathrm{~S}_{x}+x \mathrm{~S}^{0} \rightarrow \\
& \rightarrow 2 \mathrm{NaAsS}(x+1.5)+\mathrm{Cu}_{2} \mathrm{~S}+2 \mathrm{PbS} \\
& (\text { where } x=2 \text { to } 5), \\
& \mathrm{Pb}_{4} \mathrm{As}_{2} \mathrm{~S}_{7}+\mathrm{Na}_{2} \mathrm{~S}_{x}+x \mathrm{~S}^{0} \rightarrow \\
& \rightarrow 2 \mathrm{NaAsS}_{(x+1.5)}+4 \mathrm{PbS}(\text { where } x=2 \text { to } 5), \\
& \mathrm{NaAsS}_{2}+\mathrm{Na}_{2} \mathrm{~S} \rightarrow \mathrm{Na}_{3} \mathrm{AsS}_{3},
\end{aligned}
$$

\begin{tabular}{|c|c|c|c|c|c|c|}
\hline $\begin{array}{c}\text { No. of } \\
\text { experiment }\end{array}$ & $\begin{array}{c}\mathrm{NaOH} / \mathrm{S}, \mathrm{g} / \mathrm{g} \\
\text { in } 1 \mathrm{dm}^{3} \text { of solution }\end{array}$ & $\begin{array}{l}\text { Solids content, } \\
\mathrm{g} / \mathrm{dm}^{3}\end{array}$ & $\begin{array}{l}\text { Temperature, } \\
{ }^{\circ} \mathrm{C}\end{array}$ & $\begin{array}{l}\text { Size of particles } \\
(100 \%), \mathrm{mm}\end{array}$ & $\begin{array}{c}\text { Duration, } \\
h\end{array}$ & $\begin{array}{c}\text { As extraction } \\
\text { into solution, } \%\end{array}$ \\
\hline 1 & $100 / 25$ & 150 & 25 & -0.08 & 1 & 30.06 \\
\hline 3 & $100 / 25$ & 200 & 45 & $-0.1+0.08$ & 2 & 59.10 \\
\hline 4 & $100 / 25$ & 350 & 95 & $-0.5+0.315$ & 8 & 49.29 \\
\hline 6 & $100 / 100$ & 150 & 65 & $-0.1+0.08$ & 8 & 75.22 \\
\hline 7 & $100 / 100$ & 250 & 45 & $-0.5+0.315$ & 6 & 55.66 \\
\hline 8 & $100 / 100$ & 200 & 95 & $-0.315+0.2$ & 1 & 46.44 \\
\hline 9 & $100 / 100$ & 350 & 85 & -0.08 & 4 & 85.04 \\
\hline 10 & $100 / 100$ & 300 & 25 & $-0.2+0.1$ & 2 & 19.63 \\
\hline 12 & $100 / 80$ & 250 & 95 & -0.08 & 2 & 56.80 \\
\hline 13 & $100 / 80$ & 200 & 85 & $-0.2+0.1$ & 8 & 65.00 \\
\hline 14 & $100 / 80$ & 350 & 25 & $-0.1+0.08$ & 6 & 12.28 \\
\hline 15 & $100 / 80$ & 300 & 65 & $-0.5+0.315$ & 1 & 24.50 \\
\hline 16 & $50 / 100$ & 150 & 95 & $-0.2+0.1$ & 6 & 35.51 \\
\hline 17 & $50 / 100$ & 250 & 85 & $-0.1+0.08$ & 1 & 18.75 \\
\hline 18 & $50 / 100$ & 200 & 25 & $-0.5+0.315$ & 4 & 6.34 \\
\hline 19 & $50 / 100$ & 350 & 65 & $-0.315+0.2$ & 2 & 14.85 \\
\hline 20 & $50 / 100$ & 300 & 45 & -0.08 & 8 & 43.31 \\
\hline 21 & $70 / 100$ & 150 & 85 & $-0.5+0.315$ & 2 & 12,69 \\
\hline 22 & $70 / 100$ & 250 & 25 & $-0.315+0.2$ & 8 & 11.82 \\
\hline 25 & $70 / 100$ & 300 & 95 & $-0.1+0.08$ & 4 & 56.25 \\
\hline
\end{tabular}

Table 1.

Plan of the five-factor experiment $\left(X_{1-5}\right)$ at five levels 


$$
\begin{aligned}
& \mathrm{Na}_{2} \mathrm{~S}_{x}+(x-1) \mathrm{Na}_{3} \mathrm{AsS}_{3} \rightarrow \\
& \left.\rightarrow(x-1) \mathrm{Na}_{3} \mathrm{AsS}_{4}+\mathrm{Na}_{2} \mathrm{~S} \text { (where } x=2 \text { to } 5\right) .
\end{aligned}
$$

Leaching of copper skimmings of lead production was carried out at atmospheric pressure, constant temperature, and continuous stirring $\left(n=400 \mathrm{~min}^{-1}\right)$. At the end of leaching, the pulp was filtered, the filtrate and cake were analyzed for the contents of $\mathrm{As}, \mathrm{Sb}, \mathrm{Cu}, \mathrm{Pb}$, $\mathrm{Zn}, \mathrm{Fe}, \mathrm{Au}, \mathrm{Ag}$. The content of elements in solutions and cakes was determined by chemical analysis and using an optical emission spectrometer with inductively coupled plasma.

Laboratory experiments on working out the process parameters of alkaline sulfide leaching of copper skimmings of lead production were carried out according to the probabilistic-deterministic planning procedure [12]. The degree of arsenic extraction into solution has been assumed as the process efficiency assessment criterion. We have studied the dependence of the degree of arsenic extraction into solution on five factors, namely: ratio of components in the alkaline sulfide solution; solids content in the pulp; temperature; particle size; process duration.

The plan of a five-factor experiment $\left(X_{1-5}\right)$ at five levels is presented in Table. 1. Each line of the plan represents specific conditions for the separate experiment realization. Sampling from the results for point dependences of arsenic extraction into solution on the varied parameters was made by averaging the results, corresponding to each individual level (from 1 to 5). At the same time, the action of all other factors is averaged, since each of them takes all five of its levels in these experiments and thus produces self-compensation for lower (weak) and upper (strong) values.

\section{Results and discussion}

\section{Influence of the ratio of sodium hydroxide to sulfur in an alkaline sulfide solution}

The sodium hydroxide to sulfur ratio has been varied in the range of $\mathrm{NaOH} / \mathrm{S}$ from $50 / 100$ to $100 / 25 \mathrm{~g} / \mathrm{g}$ in $1 \mathrm{dm}^{3}$ of solution. At the same time, an extremum was stated at the $\mathrm{NaOH} / \mathrm{S}$ ratio value of $100 / 100 \mathrm{~g} / \mathrm{g}$ in $1 \mathrm{dm}^{3}$ of solution, and therefore an additional refining experiments were performed for the $\mathrm{NaOH} / \mathrm{S}$ ratio value equal to $90 / 100$ and $100 / 90 \mathrm{~g} / \mathrm{g}$ in $1 \mathrm{dm}^{3}$ of solution. Since the experiments were carried out outside the initial planning, the experimental parameters are identical to the conditions for the $\mathrm{NaOH} / \mathrm{S}$ factor equal to $100 / 100 \mathrm{~g} / \mathrm{g}$ in $1 \mathrm{dm}^{3}$ of solution. The parameters for conducting the experiment are listed in Table 2.

The results of experiments are shown in Fig. 2.

According to Fig. 2, the highest arsenic extraction into solution is achieved at the $\mathrm{NaOH} / \mathrm{S}$ ratio value equal to $100 \mathrm{~g} / 100 \mathrm{~g}$ in $1 \mathrm{dm}^{3}$ of the solution. The trend observed on the curve first to increasing the arsenic extraction with an increase in the $\mathrm{NaOH} / \mathrm{S}$ ratio value from 50/100 to $100 / 100$, and then to decreasing with a further increase to $100 / 25$ can be explained by different content of sulfide, polysulfide and thiosulfate forms of sulfur in the alkaline sulfide reagent obtained at different sulfur-alkali ratios. In this case, various redox conditions are produced when arsenic intermetallides are dissolved with the formation of soluble arsenate, sodium thioarsenates and sodium thioarsenites.

\section{Influence of the solids content in the pulp}

The solids content in the pulp has been varied from 150 to $350 \mathrm{~g} / \mathrm{dm}^{3}$. The results are depicted in Fig. 3 .

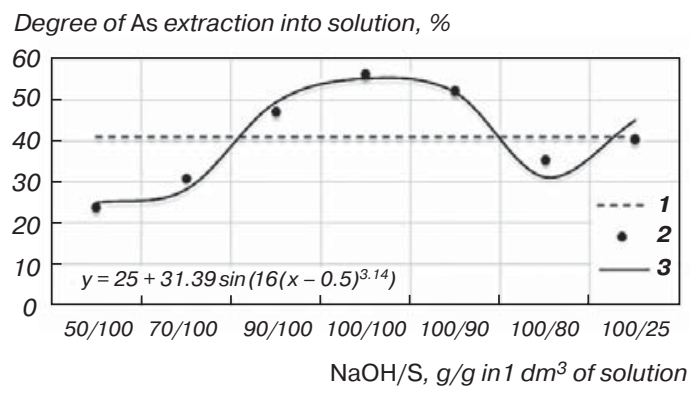

Fig. 2. Dependence of the arsenic extraction degree on the sodium hydroxide to sulfur ratio:

1 - average value; 2 - experimental samples; 3 - approximating function

Table 2

\begin{tabular}{|c|c|c|c|c|c|c|}
\hline $\begin{array}{c}\text { No. of } \\
\text { experiment }\end{array}$ & $\begin{array}{l}\mathrm{NaOH} / \mathrm{S}, \mathrm{g} / \mathrm{g} \text { in } \\
1 \mathrm{dm}^{3} \text { of solution }\end{array}$ & $\begin{array}{l}\text { Solids content, } \\
\mathrm{g} / \mathrm{dm}^{3}\end{array}$ & Temperature, ${ }^{\circ} \mathrm{C}$ & $\begin{array}{l}\text { Size of particles } \\
(100 \%), \mathrm{mm}\end{array}$ & $\begin{array}{l}\text { Duration, } \\
h\end{array}$ & $\begin{array}{c}\text { As extraction } \\
\text { into solution, } \%\end{array}$ \\
\hline 1 & $90 / 100$ & 150 & 65 & $-0.1+0.08$ & 8 & 74.23 \\
\hline 3 & $90 / 100$ & 200 & 95 & $-0.315+0.2$ & 1 & 32.58 \\
\hline 4 & $90 / 100$ & 350 & 85 & -0.08 & 4 & 82.23 \\
\hline 6 & $100 / 90$ & 150 & 65 & $-0.1+0.08$ & 8 & 79.01 \\
\hline 7 & $100 / 90$ & 250 & 45 & $-0.5+0.315$ & 6 & 31.56 \\
\hline 8 & $100 / 90$ & 200 & 95 & $-0.315+0.2$ & 1 & 50.33 \\
\hline 9 & $100 / 90$ & 350 & 85 & -0.08 & 4 & 84.12 \\
\hline 10 & $100 / 90$ & 300 & 25 & $-0,2+0.1$ & 2 & 16.75 \\
\hline
\end{tabular}

Parameters of conducting the additional refining experiments 
In the studied range of the solids content in the pulp, there is no dependence of the degree of arsenic extraction into solution on the charging copper skimmings of lead production; a slight increase in arsenic extraction into solution by $\sim 2 \%$ is within the analysis error ( Fig. 3).

\section{Influence of temperature}

The process temperature has been varied within the range from 25 to $95{ }^{\circ} \mathrm{C}$. The results of experiments are shown in Fig. 4.

\section{Influence of granulometric composition}

Size of the particles from the copper skimmings of lead production has been varied in the range from $100 \%$ less than $(-0.08 \mathrm{~mm})$ to $100 \%(-0.5+0.315 \mathrm{~mm})$. The results of experiments are illustrated in Fig. 5.

The extraction of arsenic into solution increases as decreasing is the particle size of the copper skimmings of lead production. When the particle size lessens from the fraction $(-0.5+0.315 \mathrm{~mm})$ to the fraction $(-0.08 \mathrm{~mm})$, an increase in arsenic extraction into solution by $\sim 24 \%$ is observed (Fig. 5).

\section{Influence of the process duration}

The duration of the process has been varied from one to eight hours. The results of experiments are shown in Fig. 6.

As leaching time is increased, the degree of arsenic recovery into solution increases.

Along with arsenic, a significant amount of antimony also passes into the solution. It can be noted that antimony recovery grows along with rising the extraction of arsenic into solution. Probably, antimony interacts with sodium polysulfide compounds likewise arsenic in accordance with the following reaction equations:

$$
\begin{aligned}
& 2 \mathrm{Cu}_{3} \mathrm{Sb}+\mathrm{Na}_{2} \mathrm{~S}_{x}+(x+3) \mathrm{S}^{0} \rightarrow \\
& \left.\rightarrow 2 \mathrm{NaSbS}_{\mathrm{x}}+3 \mathrm{Cu}_{2} \mathrm{~S} \text { (where } x=2 \text { до } 5\right), \\
& \mathrm{NaSbS}_{x}+(x-1) \mathrm{Na}_{2} \mathrm{~S} \rightarrow \mathrm{Na}_{3} \mathrm{SbS}_{3}, \\
& \mathrm{Na}_{2} \mathrm{~S}_{\mathrm{x}}+(x-1) \mathrm{Na}_{3} \mathrm{SbS}_{3} \rightarrow \\
& \rightarrow(x-1) \mathrm{Na}_{3} \mathrm{SbS}_{4}+\mathrm{Na}_{2} \mathrm{~S} \text { (where } x=2 \text { до } 5 \text { ). }
\end{aligned}
$$

The lead-copper precipitate, obtained by conducting the process under conditions providing about $85 \%$ extraction of arsenic into solution, contains, \%: $0.70 \mathrm{As}$; $1.17 \mathrm{Sb} ; 21.59 \mathrm{Cu} ; 39.31 \mathrm{~Pb} ; 15.32 \mathrm{~S} ; 2.27 \mathrm{Zn} ; 1.95 \mathrm{Fe}$; $11.1 \mathrm{~g} / \mathrm{t} \mathrm{Au} ; 1823.32 \mathrm{~g} / \mathrm{t} \mathrm{Ag}$.

The chemical phase analysis results have showed that arsenic in the lead-copper cake is represented in the elemental state and in the form of intermetallides in amount of $93.10 \mathrm{wt} . \%$, and in the form of sulfides and sulfosalts (6.90 wt.\%); content of antimony in the form of sulfides and sulfosalts is equal to $94.02 \mathrm{wt} . \%$, and $5.98 \mathrm{wt} . \%$ of it is in the elemental state; 93.65 wt.\% of copper are in the form of sulfides and sulfosalts, 2.4 mass $\%$ are in the form of intermetallides, and 3.95 mass $\%$ are present in the metallic state; lead content is $38.39 \mathrm{wt} \%$ in the metallic state, $42.09 \mathrm{wt} \%$ in the form of oxides and silicates, and $19.52 \mathrm{wt} \%$ - in the form of sulfides and sulfosalts.

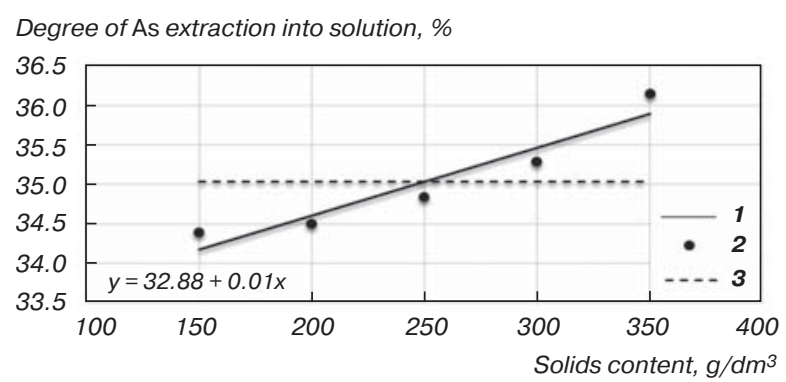

Fig. 3. Dependence of the arsenic extraction degree on the solids content in the pulp:

1 - approximating function; $2-$ experimental samples; $3-$ average value

Degree of As extraction into solution, \%

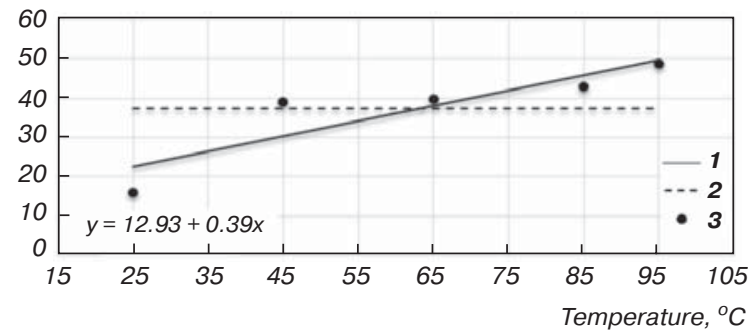

Fig. 4. Dependence of the arsenic extraction degree on the process temperature:

1 - approximating function; 2 - average value; 3 - experimental samples

Degree of As extraction into solution, \%

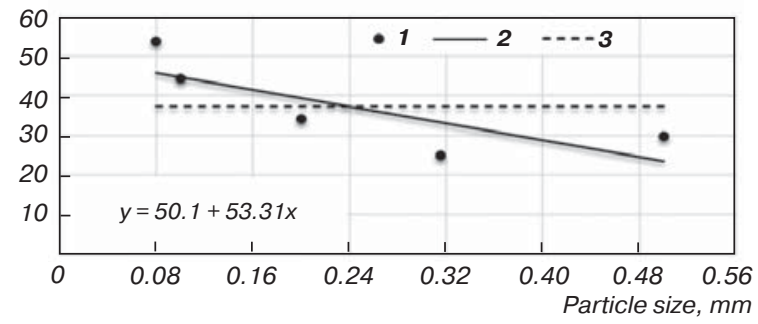

Fig. 5. Dependence of the arsenic extraction degree on the particle size of the copper skimmimgs of lead production:

1 - experimental samples; $2-$ approximating function; $3-$ average value

Degree of As extraction into solution, \%

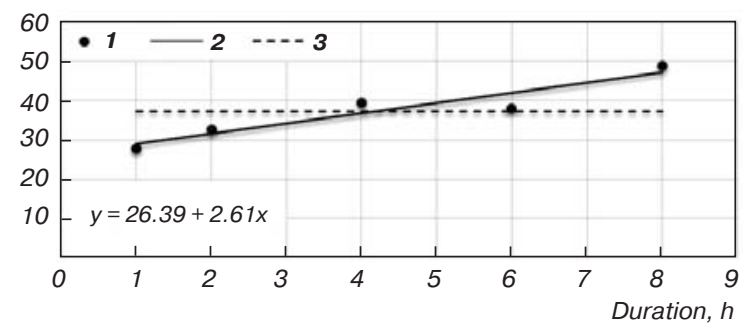

Fig. 6. Dependence of the arsenic extraction degree on the process duration:

1 - experimental samples; $2-$ approximating function; $3-$ average value 
The values of averaged results (strong and weak) for each individual level of experiment planning are used to describe the dependence of arsenic extraction into solution on varied factors. Thus, according to the results of experimental work, the parameters that have the main influence on the process of alkaline sulfide leaching of the copper skimmings of lead production are the following ones: temperature, process duration and granulometric composition, the $\mathrm{NaOH} / \mathrm{S}$ ratio in the alkaline sulfide solution.

At that, the highest arsenic recovery into solution was achieved in experiment No. 9 (Table 1), where extraction of arsenic into solution is $85.04 \%$ under the following conditions: temperature $85^{\circ} \mathrm{C}$, duration 4 hours, solids content in the pulp $350 \mathrm{~g} / \mathrm{dm}^{3}$, fraction $(-0.08 \mathrm{~mm})$, $\mathrm{NaOH} / \mathrm{S}=100 \mathrm{~g} / 100 \mathrm{~g}$ in $1 \mathrm{dm}^{3}$ of solution.

In this paper, the process of alkaline sulfide leaching is for the first time studied with reference to the copper skimmings of lead production. Within the studied range of varying the main factors, optimal conditions were determined that ensure the most complete extraction of arsenic into solution $\left(85.04 \%\right.$ As): temperature $85{ }^{\circ} \mathrm{C}$, duration 4 hours, solids content in the pulp $350 \mathrm{~g} / \mathrm{dm}^{3}$, fraction $(-0.08 \mathrm{~mm})$, ratio $\mathrm{NaOH} / \mathrm{S}=100 \mathrm{~g} / 100 \mathrm{~g}$ in $1 \mathrm{dm}^{3}$ of solution. The data obtained on physico-chemical properties of the leaching process products testify that the received lead-copper cake contains only $0.7 \%$ of arsenic, and can be dispatched either to separation of lead and copper by pyrometallurgical process, or to the charge of primary melting units of both plants, which will greatly reduce circulation of contaminant between the plants.

\section{References}

1. Nabiyeva A. A., Kulenova N. A. Review of Domestic Basis of Non-Ferrous Industry: Problems of Complex Processing of Polymetallic Raw Materials with a High Level of Impuritites. Innovations in the Field of Natural Sciences as the Basis for the Export-Oriented Industrialization of Kazakhstan: Materials of the Scientific and Practical Conference Dedicated to the 10-year Kazakhstan National Academy of Natural Sciences and the 25 th Anniversary of International Central Integrated Processing Mineral
Raw Materials of the Republic of Kazakhstan. Almaty: RSE "NC KPMS RK”, 2019. pp. 393-396.

2. Rtskhiladze V. G. Arsenic. Moscow: Izdatelstvo "Metallurgiya", 1969. $189 \mathrm{p}$.

3. Sedelnikova G. V., Kurkov A. V., Smirnov K. M. Autoclave Oxidation of Refractory Gold-Sulfide Concentrates in Russian Federation. Theory and Practice of Recent Five Years. Tsvetnye Metally. 2016. No. 8. pp. 25-32. DOI: 10.17580/tsm.2016.08.03

4. Isabaev S. M., Kuzgibekova Kh. M., Zikanova T. A., Zhinova E. V. Complex Hydrometallurgical Processing of Lead Arsenic-Containing Dust from Copper Production. Tsvetnye Metally. 2017. No. 8. pp. 33-37. DOI: 10.17580/tsm.2017.08.04

5. Naboychenko S. S., Mamyachenkov S. V., Karelov S. V. Arsenic in Nonferrous Metallurgy. Ekaterinburg: UrO RAN, 2004. $238 \mathrm{p}$.

6. Kopylov N. I., Kaminsky Yu. D. Arsenic. Novosibirsk: Sibirskoe Universitetskoe Izdatelstvo, 2004. 367 p.

7. Anderson C. G., Twidwell L. G. The Alkaline Sulfide Hydrometallurgical Separation, Recovery and Fixation of Tin, Arsenic, Antimony, Mercury and Gold. SAIMM. Lead and Zinc. 2008. pp. 121-132.

8. Anderson C. G. The Treatment of Arsenic Bearing Ores, Concentrates and Materials with Alkaline Sulfide Hydrometallurgy. Arsenic Metallurgy: Fundamentals and Applications. TMS. 2005. pp. 255-263.

9. Anderson C. G. Alkaline sulfide leaching technology; just the facts. Proceedings Of The $7^{\text {th }}$ International Symposium. Hydrometallurgy. 2014. Vol. 1. pp. 77-88.

10. Ponomareva E. I., Solovyeva V. D., Bobrova V. V. Arsenic in Lead-Zinc And Copper Industry. Kompleksnoye Ispolzovanie Mineralnogo Syriya. Vestnik AN KazSSR. 1978. pp. 66-71.

11. Amir Mohammad Nazari, Rebecca Radzinski, Ahmad Ghahreman. Review of Arsenic Metallurgy: Treatment of Arsenical Minerals and the Immobilization of Arsenic. Hydrometallurgy. 2017. Vol. 174. pp. 258-281.

12. Malyshev V. P. Probabilistic-Deterministic Experiment Planning. Alma-Ata: Science of the Kazakh SSR, 1981.116 p.

13. Liu Z.-X., Sun L., Tang L.-D., Hu J., Xiao Y., Chen Y.-G., Yin Z.-L. Removal of Metallic Impurities from Off-Grade Copper Concentrate in Alkaline Solution. International Journal of Nonferrous Metallurgy. Vol. 7, Iss. 2. 2018. pp. 9-23. 